\title{
Influence of overlearning on single habit reversal in naive rhesus monkeys'
}

\author{
HENRY A. CROSS ${ }^{2}$ AND WILLIAM N. BOYER \\ UNIVERSITY OF WISCONSIN PRIMATE RESEARCH CENTER
}

Naive rhesus monkeys, trained to a criterion on a visual discrimination task, were given reversal trials on the same problem after either 6 or 126 additional trials. The two groups did not differ in visual performance as would have been predicted by the overlearning reversal effect. This failure is not easily attributable to procedural variation which has been present in previous primate studies, and it suggests the possibility of phylogenetic differences in habit reversal problems.

Recent investigations with monkeys (Boyer \& Cross, 1965; Cross \& Brown, 1965; Cross et al, 1964) and with preschool children (Vaughter \& Cross, 1965) have failed to show the overlearning reversal effect (ORE), i.e., more rapid habit reversal following overtraining. While negative findings are not unique even in ORE studies with rats (D'Amato \& Schiff, 1964; Paul, 1965), the primate studies in which the ORE has failed to occur have differed procedurally from the rat studies to the extent that comparability is questionable. In one of the primate studies (Cross et al, 1964) initial training was greatly extended, but even the results of this investigation may not have been definitive because the number of reversal trials was smaller than typically found in rat studies and each $S$ received several successive reversal problems. Accordingly, the present brightness discrimination experiment with primates was designed to approximate the procedure of previous tests of ORE with rodents.

\section{Method}

Ss were 14 experimentally naive male rhesus monkeys, 4-5 years of age. Pretraining consisted of adapting Ss to the WGTA and training them in short daily sessions to displace a single unpainted block covering a baited foodwell. The WGTA with a conventional formboard was used. Stimuli were two $3 \times 3 \times 3 / 4$-in. blocks, one painted grey and one white, and each was readily discriminable from the aluminum-colored formboard.

Pretrained Ss were randomly divided into two groups of seven Ss each. One group was designated the criterion learning (CL) group and the other the overlearning (OL) group. All Ss were run 24 noncorrection trials per day on the same brightness discrimination problem. The initially nonpreferred block was rewarded(raisins) until the criterion of 20 correct out of 24 successive trials, with the last six responses correct, was obtained. Rewarded position was randomized, but balanced over 24 daily trials. The Ss were given continuous daily testing until the criterion was met.
In the session after reaching criterion Ss in Group CL received six additional trials on the original problem, and immediately thereafter they were given the reversal problem under the same procedure and criterion as was used in the original problem. When Ss in Group OL met criterion, they were given 120 postcriterion trials on the original problem (five additional days) before receiving the same reversal problem as did Ss in Group CL. Both groups received the reversal problem for at least six consecutive days, even though some ss had met criterion earlier.

Results

The mean trials-to-criterion (TTC) scores for the original discrimination were 75.43 and 68.57 for Groups CL and OL, respectively. These means were not significantly different $(F=.25 ; \mathrm{df}=1 / 12)$. During the overlearning period Group OL Ss were correct in $98 \%$ of their responses, with only 16 incorrect choices in a total of 882 trials.

The mean TTC scores for the reversal problem were 147.43 for Group CL and 106.29 for Group OL. While this difference appears large and is in the appropriate direction to support the ORE, it is largely the result of one aberrant $S$ in Group CL who took 288 trials to reach criterion. Statistical analysis failed to show a significant mean difference $(F=1.65 ; \mathrm{df}=1 / 12 ; \mathrm{p}<.25)$. Mean errors-to-criterion (ETC) scores of 72.14 and 55.86 were obtained by Groups CL and OL, respectively. Statistical analysis of ETC scores also indicated no significant mean difference $(F=1.19 ; \mathrm{df}=1 / 12)$. Since all Ss were tested on the reversal for at least six days, another two-factor analysis of variance of daily total correct responses was done with the following results: Groups $(F=.48 ; \mathrm{df}=1 / 12)$, Days $(F=102.41 ; \mathrm{df}=5 / 60$; $\mathrm{p}<.001)$ and Groups by Days $(\mathrm{F}=1.54 ; \mathrm{df}=5 / 60 ; \mathrm{p}<.25)$.

\section{Discussion}

Failure to obtain an ORE in a visual discrimination problem has been reported in two studies with monkey Ss (D'Amato, 1965; Tighe, 1965) after the present research was completed. Since these two studies were procedurally similar to the present investigation and to those in which ORE has previously been reported, the conclusion seems warranted that the discrepant results cannot be attributable simply to procedural differences in previous primate studies. In five experiments using infrahuman primates (Boyer \& Cross, 1965; Cross \& Brown, 1965; Cross et al, 1964; D'Amato, 1965; Tighe, 1965), and in one with childran (Vaughter \& Cross, 1965) there has been no evidence 
of an ORE. In addition to the problems already under consideration in the ORE area (Mackintosh, 1965; Paul, 1965; Sperling, 1965a, 1965b; Theios \& Blosser, 1965), it is likely that an additional one, that of phylogenetic level, will also require attention.

\section{References}

Boyer, W. N., \& Cross, H. A. Discrimination reversal learning in naive stump-tailed morkeys as a function of number of acquisition trials, Psychon. Sci., 1965, 2, 139-140.

Cross, H. A., \& Brown, L. T. Discrimination reversal learning in squirrel monkeys as a function of number of acquisition trials and prereversal experience. J. comp. physiol. Psychol., 1965, $59,429-431$.

Cross, H. A., Fickling, R. M., Carpenter, J. B., \& Brown, L. T. Discrimination reversal performance in squirrel monkeys as a function of prereversal experience and overlearning. Psychon. Sci., $1964,1,353-354$

D'Amato, M. R. The overlearning reversal effect in monkeys provided a salient irrelevant dimension. Psychon. Sci., 1965, 3, 21-221.

D'Amato, M. R., \& Schiff. D. Further studies of overlearning and position reversal learning. Psychol. Rep., 1964, 14, 380-382.

\section{Comment on Myers et al}

by Stanley Wechkin and Gene P. Sackett

Myers, Horel, \& Pennypacker (1965) claim to have established operant control over a vocal response (VR) in Cebus albifrons. Unfortunately, it is not clear from their report that the VR functioned as an operant, i.e., as an instrumental response, rather than as a respondent. If the $\mathrm{VR}$ is one which would ordinarily be elicited by the presence or anticipation of the US, that is, if the VR were a food call, then the association of the VR with the $\mathrm{S}^{\mathrm{D}}$ would be a case of classical conditioning. Unfortunately, we know of no published report in which the food call of this species is adequately described. However, the VR used by Myers et al, namely, one with a frequency of 1000-3000 cps and a duration greater than $0.1 \mathrm{sec}$. is almost identical to a food call of the rhesus (Rowell \& Hinde, 1962) and is probably the same as the food call described by Van Hooff (1962) for a large number of species, including Cebus albifrons. It has been frequently observed in zoos and laboratories that this type of VR becomes associated with a particular stinulus, e.g., the appearance of the caretaker who does the feeding. However, to call any response associated with a stimulus an operant is to make the term operant so broad as to deprive it of distinctiveness.

This is not to deny that a primate vocalization can come under operant control. However, even if the authors had unequivocally demonstrated this, their conclusion that "the vocal responses of nonhuman animals and humans seem to be acquired and maintained in basically the same way" would still not follow. The proposition that a response can come under operant control is not identical to one stating that the presence of the response in a larger population is also predicated on operating conditioning. Thus for example, Brener (1965) has recently shown
Mackintosh, $\mathbf{N}$. J. Selective attention in animal discrimination learning. Psychol. Bull., 1965, 64, 124-150.

Paul, C. Effects of overlearning upon single habit reversal in rats. Psychol. Bull., 1965, 63, 65-72.

Sperling, S. E. Reversal learning and resistance to extinction: a supplementary report. Psychol. Bull., 1965, 64, 310-312.

Theios, J., \& Blosser, D. An incentive model for the overlearning reversal effect. Psychon. Sci., 1964, 2, 37-38.

Tighe, T.J. Effect of overtraining on reversal and extra-dimensional shifts. J. exp. Psychol., 1965, 70, 13-17.

Vaughter, R. M., \& Cross, H. A. Discrimination reversal performance in children as a function of prereversal experience and overlearning. Psychon. Sci., 1965, 2, 363-364.

\section{Notes}

1. Supported in part by NrH grant FR-0167 and Army Chemical $R$ \& D Laboratories Contract DA18-035-AMC-135(A) to the University of Wisconsin Primate Laboratory. We thank H. F. Harlow and V. J. Polidora for their cooperation, support and assistance. In conducting the research reported herein, the investigators adhered to the "Principle of Laboratory Animal Care" as established by the National Society for Medical Research.

2. Texas Technological College.

that heart rate can come under operant control, but this is very far from saying that heart rate is a behavior acquired through shaping, selective reinforcement, etc.

In the Wisconsin Primate Laboratory monkeys have been reared in complete isolation, where they have no physical, visual, or auditory contact with other species members, and hence where reinforcement contingencies for vocalizations were absent. These animals do vocalize. Observations during the isolation period by one of us (GPS) indicate that isolates produce essentially the same sounds as non-isolates, although with a lower frequency of occurrence. This suggests that few, if any, of the vocalizations of laboratoryreared rhesus monkeys are acquired through conditioning. Furthermore, when isolates were later tested for social behavior some of their vocalizations were "socially appropriate," e.g., cooing under stress, and barking and screeching during aggression. This implies that at least some vocalizations are innate, and depend upon nothing more than appropriate releasing stimuli for evocation and maintenance. Thus, while it may be true that many vocalizations of monkeys can be brought under operant control, this alone does not prove that operant conditioning is either necessary or sufficient for normal development of nonhuman primate vocalization.

\section{References}

Brener, J. Some effects of augmented sensory feedback from the heart. Presented at the Psychonomic Society, Chicago, 1965.

Myers, S. A., Horel, J. A., \& Pennypacker, H. S. Operant control of vocal behavior in the monkey Cebus albifrons. Psychon. Sci., $1965,3,389-390$

Rowell, T. E., \& Hinde, R. A. Vocal communication by the rhesus monkey, Proc. Zool. Soc. London, 1962, 138, 279-294.

Van Hooff, J. A. R. A. M. Facial expressions in higher primates. Symp. Zool. Soc. London, 1962, 8, 97-125.

For reply by Pennypacker, Horel and Myers see page 254 . 